\title{
IMPLEMENTASI PEMBELAJARAN FISIKA MELALUI PEMROSESAN TOP DOWN TERHADAP HASIL BELAJAR FISIKA SISWA SMA KELAS $X$
}

\author{
Aisyah Azis ${ }^{1}$, Muhammad Aqil Rusli ${ }^{1}$, A. Momang Yusuf ${ }^{1}$ \\ ${ }^{1}$ Program Studi Pendidikan Fisika, Jurusan Fisika, FMIPA UNM Makassar \\ E-mail: aisyahazisunm@gmail.com
}

\begin{abstract}
This paper describes the results of learning physics that begins with the complex questions that require integration of multiple knowledge to resolve the question. In the learning process, students were trained to plan for a settlement of the problem by first identifying the required amount of physical quantities. This learning guided students to learn according to their needs in solving the problem, in this case using a top down approach to processing. This learning involved student's assimilation and accommodation in planning and solving problem involving both, the students will be motivated to participate in the learning process. Physics student learning outcomes obtained after following study at the high category, which showed that not only motivated to follow the lesson, but also they able to achieve a high score
\end{abstract}

Keywords: top down approach, physics achievement

Fisika merupakan mata pelajaran yang sangat menarik untuk dikaji sebab pelajaran ini sangat identik dengan fenomena yang terjadi dalam kehidupan. Melalui pelajaran fisika, sikap ilmiah seperti jujur, obyektif, terbuka, ulet, kritis dan bekerjasama dengan orang lain, diharapkan dapat dikembangkan. Selain itu, Standar Ketuntasan Lulusan menuntut siswa mampu melakukan percobaan, dengan keterampilan proses sains yang meliputi: 1) merumuskan masalah;2) mengajukan dan menguji hipotesis; 3 ) menentukan variabel; 4) merancang dan merakit instrumen; 5) mengumpulkan, mengolah dan menafsirkan data; 6) menarik kesimpulan; 7) mengkomunikasikan hasil percobaan secara lisan dan tertulis (BSNP, 2006).

Kondisi pembelajaran yang ada pada SKL mengindikasikan bahwa siswa merupakan agen aktif dalam mengkonstruksi informasi yang mereka peroleh. Namun pada kenyataannya, sebagian besar siswa menjadi pasif dalam mengikuti pembelajaran, dimana mereka hanya menjadi pendengar selama proses pembelajaran. Sedangkan hasil penelitian menegaskan bahwa siswa sudah tidak tertarik dan tidak fokus pada pembelajaran setelah 7 sampai 
15 menit mendengarkan ceramah guru (Bonwell \& Eison, 1991)

Permasalahan yang dialami siswa dalam belajar fisika adalah mereka sangat mudah lupa materi fisika yang telah mereka pelajari. Selain itu, mereka tidak mampu menerapkannya dalam menjelaskan fenomena alam yang mereka temui di kehidupan sehari-hari. Keadaan ini menjadikan fisika kurang diminati, bahkan fisika menjadi mata pelajaran yang ditakuti oleh siswa.

Keadaan ini sering ditemui di beberapa sekolah dan salah satunya adalah SMA Negeri 1 Tinambung Kabupaten Polewali Mandar. Bagi siswa, fisika sulit dipahami karena membutuhkan kemampuan siswa dalam memanipulasi variabel matematika dengan baik. Selain itu, siswa harus menghafal persamaanpersamaan yang dibutuhkan dalam menjawab soal.

Melihat pembelajaran fisika yang selalu menjadi permasalahan bagi siswa, maka sudah selayaknya fisika diajarkan dari zone of current development, dengan mengangkat fenomena yang dapat dijumpai dalam kehidupan sehari-hari. Pembelajaran fisika dapat dimulai dari proses akomodasi pengetahuan yang siswa miliki untuk menjawab pertanyaan yang dekat dengan kehidupan mereka, jika jawaban tersebut tidak sesuai dengan fakta yang mereka dapati, maka siswa perlu difasilitasi untuk melakukan asimilasi dalam mengkonstruk pengetahuan. Kondisi ini akan membantu siswa yang mengalami ketidakseimbangan kognitif menjadi termotivasi untuk mengikuti proses pembelajaran.

Suatu pendekatan pembelajaran yang dapat digunakan dalam memfasilitasi proses konstruksi pengetahuan adalah pendekatan pemrosesan top down.

Pada pembelajaran pemrosesan top-down, siswa secara aktif menghubungkan informasi lama dengan informasi baru yang mereka peroleh, kemudian mengubah informasi lama tersebut apabila sudah tidak sesuai. Pandangan ini mempunyai implikasi yang sangat besar bagi pengajaran karena menyarankan peran yang jauh lebih aktif bagi siswa dalam pembelajaran. Pembelajaran ini berpusat pada siswa, dimana guru mendampingi siswa menemukan makna mereka sendiri, bukannya mengajari dan menguasai semua kegiatan di ruang kelas (Slavin 2009).

Proses pembelajaran di sekolah yang terjadi selama ini menganut bottom-up yang menggambarkan pendekatan dimana persepsi dimulai dari rangsangan. Misalnya, siswa belajar dengan memperhatikan informasi baru yang disampaikan oleh guru secara bertahap. Berbeda dengan top-down atau yang dikenal dengan konstruktivis (Bruner,1957; Gregory, 1980; Rock, 1983; von Helmholtz, 1906/1962) dalam (Sternberg and Sternberg 2012), siswa berusaha mengkonstruksi pemahaman terhadap sebuah stimulus yang diberikan guru. Pada kondisi ini, siswa dapat diperlihatkan fenomena yang sering dijumpai dalam kehidupan sehari-hari sehingga perseptor yang menerima informasi tersebut mempengaruhi kognisi siswa untuk mencari jawaban Hal menarik tentang teori persepsi konstruktif (top-down) adalah bahwa teori ini menghubungkan kecerdasan manusia 
meskipun pada proses dasar dari sebuah persepsi. Menurut teori ini, persepsi tidak hanya terdiri dari proses kognitif tingkat rendah, tetapi sebenarnya melibatkan proses kognisi tingkat tinggi yang berinteraksi dan dipandu oleh kecerdasan manusia.
Untuk membedakan bottomup dan top-down, dapat dilihat dari Gambar alur pemrosesan informasi berikut. (Sternberg and Sternberg 2012)

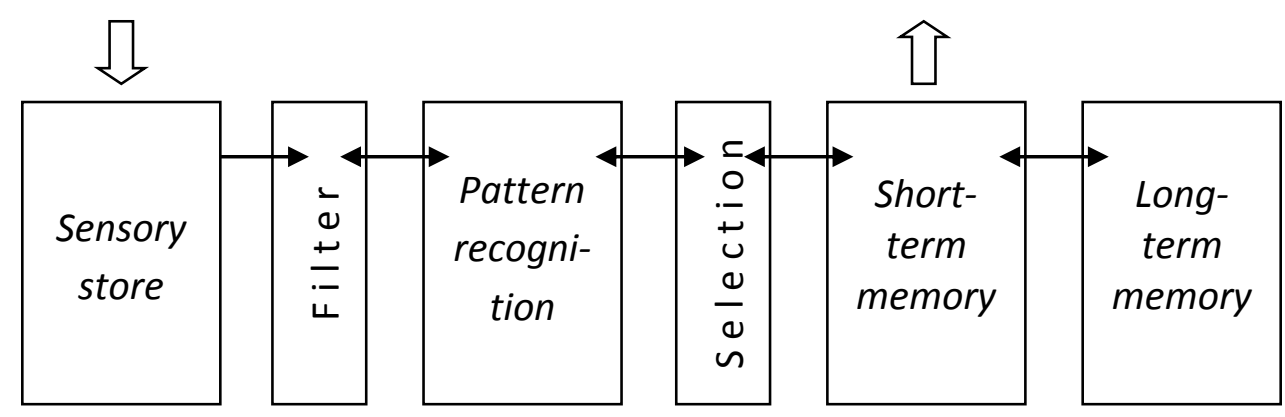

Gambar 1. Alur pemrosesan informasi

Tahap sensory store merupakan tempat penyimpanan informasi sementara berdasarkan bentuk sensor sebenarnya, Informasi pada sensory store hilang kecuali informasi tertentu yang dapat dikenali pada tahap pattern recognition. Ketika kita sudah terbiasa dengan informasi tersebut, maka kita akan menggunakan informasi yang sudah ada di memori untuk mengenalinya.

Beberapa pakar menyatakan bahwa kita hanya mampu mengenali satu perilaku dalam satuan waktu. Mereka mengatakan bahwa perhatian merupakan filter dan selection yang membatasi perilaku yang akan dikenali ketika banyak perilaku yang datang secara bersamaan. Selain itu, para ahli juga berpandangan bahwa ada banyak perilaku yang dapat dikenali tapi hanya sebagian saja yang dapat diingat, sedangkan yang lain segera dilupakan.

Tahap selanjutnya adalah short-term memory (STM). Memori ini dibatasi oleh kapasitas informasi yang dapat disimpan dan durasi waktu penyimpanan. Sebagai contoh, kebanyakan orang dewasa mudah mengingat tujuh digit nomor telepon, sedangkan untuk mengingat sepuluh digit nomor akan sangat susah. Selain itu, STM yang dibatasi oleh waktu dapat diilustrasikan dengan contoh berikut. Kita mudah melupakan nomor telepon jika kita tidak mengulang-ulanginya. Sedangkan Long-term memory (LTM) tidak dibatasi oleh keduanya, yaitu tidak terbatas oleh sejumlah informasi dan untuk melupakan informasi yang ada pada LTM relatif lebih lambat. Deskripsi tentang proses informasi di atas yang diawali dari sensory store sampai ke LTM disebut juga pemrosesan bottom-up, namun jika sensory store diletakkan di akhir dan LTM di awal maka proses informasi tersebut disebut sebagai pemrosesan top-down.

Para pakar konstrtuktivis berpandangan bahwa kita selalu membuat atribusi yang benar 
mengenai sensasi visual kita. Alasannya karena secara tidak sadar kita telah melakukan inferensi, sebuah proses dimana kita tidak sadar menyerap informasi dari sejumlah sumber untuk menciptakan persepsi (Snow and Mattingley, 2003) dalam (Sternberg and Sternberg 2012). Hal ini menekankan pentingnya pengetahuan awal yang dikombinasi-kan dengan informasi yang relatif sederhana dari reseptor sensorik. Pada pembelajaran fisika melalui pendekatan pemrosesan top down, siswa akan diberi tantangan yang mengaitkan antara pengetahuan awal mereka dengan informasi yang mereka butuhkan untuk menjawab tantangan tersebut.

Piaget mengemukakan bahwa asimilasi memungkinkan organisme merespon situasi sekarang sesuai dengan pengetahuan sebelumnya. Jika aspek unik dari situasi ini tidak dapat direspon, maka hal ini dapat menyebabkan ketidak seimbangan kognitif. Adanya kebutuhan bawaan untuk mencapai keseimbangan, maka struktur mental akan berupaya untuk mencapai keseimbangan kognitif.

Gestalt menjelaskan bahwa kurangnya keseimbangan kognitif memiliki sifat motivasional yang membuat organisme aktif sampai keseimbangan tercapai kembali (Hergenhahn and Olson 2009).

Menurut Piaget, pendidikan membutuhkan pengalaman yang menantang bagi siswa sehingga proses asimilasi dan akomodasi dapat menumbuhkan kemampuan atau intelektual (Hergenhahn and Olson 2009). Akomodasi meliputi proses perubahan (adaptasi) skema lama untuk memproses informasi dan objek baru di lingkungannya (Solso, Maclin et al. 2008).

Akomodasi terjadi ketika siswa menyesuaikan skema mereka agar sesuai dengan informasi dan pengalaman baru mereka (Santrock 2008). Menurut pandangan Piaget siswa pada usia SMA merupakan siswa yang sudah berada pada tahap perkembangan operasional formal. Pada tahap ini, individu-individu sudah mulai mengambil keputusan berdasarkan pengalaman nyata dan berpikir lebih abstrak, idealis dan logis. Kualitas abstrak dari pemikiran operasional formal terlihat nyata dalam pemecahan masalah secara verbal. Jika individu memiliki kemampuan berpikir abstrak dari tahap operasional formal, maka dia akan mampu mengidealisasikan berbagai kemungkinan. Dalam hal ini mereka berpikir lebih seperti ilmuwan. Mereka menyusun rencanarencana untuk memecahkan masalah dan secara sistematis menguji berbagai solusi.

Pentingnya pembelajaran fisika dan membantu siswa mengkonstruksi pengeetahuan mereka sendiri, maka dilakukan pembelajaran fisika melalui pemrosesan top down yang bertujuan mengetahui hasil belajar fisika siswa SMAN 1 Tinambung, Kabupaten Polewali Mandar setelah mengikuti proses pembelajaran fisika melalui pemrosesan top down.

\section{METODE}

Penelitian ini merupakan penelitian kuantitatif dengan desain post test only control group design. Subjek penelitian adalah siswa kelas $X$ IPA SMA Negeri 1 Tinambung Kabupaten Polewali Mandar, 
Sulawesi Barat yang memiliki dasar kemampuan manipulasi 3 variabel matematis yang cukup baik. Dari hasil observasi diperoleh 8 orang siswa. Metode tes digunakan untuk memperoleh data hasil belajar fisika setelah dilakukan pembelajaran, dan data tersebut dijelaskan melalui pengkategorian skor.

\section{HASIL DAN PEMBAHASAN}

Berdasarkan skor hasil pembelajaran fisika siswa, diperoleh data sebagai berikut:

Tabel 1. Kategori skor hasil belajar fisika

\begin{tabular}{cccc}
\hline No & Rentang & Persentase & Kategori \\
\hline 1 & $25-30$ & 62,5 & Sangat tinggi \\
2 & $19-24$ & 37,5 & Tinggi \\
3 & $13-18$ & 0 & Sedang \\
4 & $7-12$ & 0 & Rendah \\
5 & $0-6$ & 0 & Sangat rendah \\
\hline
\end{tabular}

Data skor hasil belajar fisika yang diperoleh mendeskripsikan bahwa skor siswa secara keseluruhan telah mencapai ketuntasan belajar, dimana $62,5 \%$ siswa berada pada kategori sangat tinggi dan 37,5\% lainnya berada pada kategori tinggi.

\section{Pemrosesan top-down}

Implementasi pembelajaran fisika melalui pemrosesan top down membuat siswa aktif dalam mengkonstruksi pengetahuan.

a. Pemberian tantangan

Setelah mereka diberi tantangan, yaitu menentukan panjang ruang kelas dengan menggunakan mobil Tamiya, mereka kemudian berpikir, besaran fisika apa yang dibutuhkan untuk menentukan panjang ruang kelas. Untuk menentukan besaran tersebut, guru memberi bimbingan pada siswa dengan memperlihatkan mobil Tamiya dan menanyakan besaran fisika apa saja yang dapat diukur dari gerak sebuah mobil Tamiya.

Dari pertanyaan tersebut siswa diminta untuk menuliskan besaran yang dapat diketahui, kemudian mereka diminta untuk merancang suatu tahapan untuk mengukur besaran tersebut. sebagian siswa bertanya, bagaimana cara mengukur kecepatan mobil Tamiya? Pertanyaan ini merupakan sebuah ekspresi bahwa terjadi proses akomodasi pada diri siswa yang berujung pada motivasi atau rasa ingin tahu. Keadaan ini akan memicu pembelajaran yang muncul dari keinginan intrinsik. Ketika belajar dimulai dari diri pelajar, maka hal itu akan menjadi proses generatif di mana pembelajar berusaha untuk menciptakan sesuatu yang baru untuk membawa ide atau strategi menjadi ada (Castleberry, 2000). Kondisi seperti inilah yang membuat pembelajaran fisika melalui pemrosesan top down menjadi bermakna bagi siswa karena mereka belajar sesuai kebutuhan mereka. Seperti yang dikemukakan oleh salah seorang siswa

"Saya sangat setuju bila pelajaran fisika diawali dengan tantangan, karena dapat melatih cara berpikir seorang siswa, seperti kami ini, karena dulunya saya tidak terlalu mengerti dengan suatu permasalahan dalam bentuk tantangan dan dengan 
mengikuti belajar ini saya dapat berpikir kritis".

Dengan membiasakan pemberi-an tantangan, secara perlahan siswa diharapkan mampu melihat setiap fakta terkait pelajaran fisika yang mereka temui dalam kehidupan sehari-hari. Setelah mengetahui fakta tersebut, siswa akan belajar menjelaskan kejadian-kejadian yang mereka temui berdasarkan konsep fisika. Hal ini sejalan dengan tujuan pembelajaran fisika, yaitu agar siswa mampu mengembangkan kemampuan bernalar dalam berpikir analisis induktif dan deduktif dengan menggunakan konsep dan prinsip fisika untuk menjelaskan berbagai peristiwa alam dan menyelesaian masalah baik secara kualitatif maupun kuantitatif (BSNP, 2006). Uraian di atas merupakan tahap awal kegiatan pembelajaran melalui pendekatan pemrosesan top down yang dicirikan oleh permasalahan kompleks yang jawabannya terdiri dari konsep dan hukum fisika. Pemilihan masalah yang akan ditampilkan pada awal pembelajaran harus mudah dipahami dan dapat dibuktikan secara faktual di hadapan siswa. Hal ini dimaksudkan agar siswa memiliki rasa ingin tahu terhadap materi yang akan mereka eksplorasi dalam menjelaskan permasalahan yang didemonstrasikan tersebut.

b. Siswa sebagai penentu materi

Motivasi awal yang telah berhasil menarik minat belajar fisika bukanlah jaminan bahwa siswa akan tetap senang untuk belajar hingga akhir jam pelajaran. Justru langkah yang ditempuh oleh guru setelah fase tantangan akan menjadi penentu apakah motivasi tersebut mampu bertahan hingga akhir jam pelajaran atau tidak. Ini merupakan tantangan yang luar biasa bagi setiap guru, sebab guru adalah penentu apakah waktu 90 menit akan menjadi waktu yang membosankan, atau bahkan masa yang menakutkan bagi siswa ataukah guru akan memfasilitasi siswa dengan suasana kelas yang dapat mereka nikmat hingga akhir pelajaran? Tentu saja jawaban dari pertanyaan itu tercermin dari cara seorang pengajar mendesain pembelajaran di kelas. Dan penulis dalam hal ini peneliti tentu menginginkan proses pembelajaran yang dapat dinikmati oleh siswa hingga akhir jam pelajaran.

Upaya melibatkan siswa dalam penentuan materi ajar sangatlah penting, sebab hal ini dapat meyakinkan bahwa mereka benarbenar terlibat dalam pembelajaran, sehingga ingatan mereka akan meningkat (Conway, Cohen, \& Stanhope, 1991). Pembaca mungkin akan berpikir bagaimana mungkin siswa dapat menentukan materi yang harus mereka pelajari sedangkan mereka sendiri tidak tahu? Bisa jadi para pembaca mempertanyakan hal ini sebab disadari sepenuhnya bahwa siswa belum pernah mempelajari materi tersebut, namun melalui hasil penelitian yang penulis temukan bahwa siswa dapat dibantu dalam menetapkan apa yang perlu mereka ketahui. Cara yang dapat ditempuh adalah melalui identifikasi fakta. Melalui identifikasi fakta, siswa dipandu untuk mengklasifikasikan kejadian-kejadian yang mereka amati pada demonstrasi, yang kemudian akan mereka kaji melalui tahap eksplorasi 
c. Eksplorasi pengetahuan

Tahap kedua yang tidak kalah penting dari tahap pertama adalah bagaimana guru mendesain proses eksplorasi yang akan siswa lakukan dalam menemukan jawaban pertanyaan pada LKS. Salah satu cara yang dapat ditempuh untuk mengaktifkan siswa dalam pembelajaran adalah dengan membagi siswa ke dalam beberapa kelompok. Aronson dalam penelitian teknik belajar kelompok menemukan bahwa siswa mempelajari materi lebih cepat dan secara signifikan lebih baik pada hasil ujian dibandingkan kondisi kontrol siswa di kelas dengan instruksi secara tradisional (Hanze \& Berger, 2007)

Untuk memfasilitasi siswa melakukan eksplorasi terhadap materi yang akan dipelajari, penulis telah menyusun lembar kerja siswa sebagai panduan dalam melakukan eksplorasi untuk menentukan kecepatan mobil tamiya. Melalui lembar kerja tersebut, siswa akan mencari informasi tentang besarnya kecepatan mobil Tamiya. Dari hasil pengamatan, peneliti menemukan bahwa sebagian siswa belum mampu melakukan pengukuran dengan teliti dan cara pengambilan data masih tidak valid. Hal ini dipertegas oleh pengakuan siswa yang menyatakan bahwa mereka sangat jarang melakukan praktikum. Akibatnya, peneliti harus berpindah dari kelompok satu ke kelompok yang lain untuk mengingatkan siswa tentang pentingnya ketelitian dalam melakukan pengukuran dan pengamatan.

d. Evaluasi pembelajaran

Evaluasi hasil pembelajaran dalam kelas dimaksudkan untuk mengetahui sejauh mana pemahaman siswa terhadap pelajaran mereka. Pada tahap pemberian contoh dan soal latihan, penulis menemukan dua hal yaitu siswa mampu menyelesaikan soal yang berada pada level penerapan, namun untuk soal analisis, mereka masih mengalami kesulitan. Seperti menentukan titik temu dua mobil Tamiya yang saling berkejaran dengan data yang disajikan berupa data perpindahan dan waktu.

\section{SIMPULAN DAN SARAN}

Hasil implementasi pembelajaran fisika melalui pemrosesan top down menunjukkan bahwa 37,5\% siswa berada pada kategori tinggi, dan $62,5 \%$ siswa berada pada kategori sangat tinggi. Data ini menunjukkan bahwa pemrosesan top down dapat digunakan sebagai salah satu solusi pembelajaran fisika yang dapat membimbing siswa mengkonstruksi pengetahuan awal mereka menjadi suatu pengetahuan baru berdasarkan permasalahan yang ditampilkan oleh guru di kelas.

Pentingnya desain pembelajaran fisika melalui pemrosesan top down yang mampu mengajarkan siswa cara berpikir, tentunya membutuhkan banyak pikiran. Salah satu hal utama yang perlu didesain sebaik mungkin dalam pembelajaran ini adalah pemilihan tantangan. Tantangan yang diberikan di kelas sebaiknya masih terhubung dengan konsepsi awal siswa sehingga proses asimilasi dan akomodasi dapat terwujud di kelas. Oleh karena itu, menyadari akan pentingnya pemilihan tantangan dalam pemrosesan top down, maka pemilihan tantangan sebaiknya didasarkan pada kejadiankejadian yang dapat dijumpai oleh 
siswa dalam kehidupan sehari-hari, dan tantangan yang baik adalah dapat menimbulkan ketidakseimbangan kognisi.

\section{DAFTAR PUSTAKA}

Bonwell, C. C., \& Eison, J. A. (1991). Active learning: Creating excitement in the classroom. Washington D C: George Washington University.

BSNP. (2006). BSNP-Indonesia. Retrieved October 19, 2011, from http://bsnpindonesia.org /id/? pageid $=103 /$

Castleberry, P. J. W. a. M. S. (2000). Educators as learners. Creating a professional learning community in your school. Alexandria, Virginia USA: ASCD.

Conway, M. A., Cohen, G., \& Stanhope, N. (1991). On the very long-term retentionof knowledge acquired through formal education: twelve years of cognitive psychology. Journal of Experimental Psychology, Vol.34, No.120.
Hanze, M., \& Berger, R. (2007). Cooperative learning, motivational effects, and student characteristics: An experimental study comparing cooperative learning and direct instruction in 12th grade physics classes. Learning and Instruction, Vol.7, 29-41.

Hergenhahn, B. R., \& Olson, M. H. (2009). Theories of Learning. Jakarta: Kencana.

Santrock, J. W. (2008). Educational Psychology. New York: McGraw Hill.

Slavin, R. E. (2009). Psikologi Pendidikan. Boston: Allyn and Bacon.

Solso, R. L., Maclin, O. H., \& Maclin, M. K. (2008). Cognitive Psychology. Jakarta: Erlangga.

Sternberg, R. J., \& Sternberg, K. (2012). Cognitive Psychology (Sixth ed.). USA: Wadsworth, Cengage Learning. 